\title{
EFFECT OF DOPING AGENT ON ELUTION PROFILE OF TC-99M GENERATIONAND LABELING OF TC-99M WITH
}

\author{
${ }^{1}$ Ruhul Amin M*., ${ }^{2}$ Azizul Haque, ${ }^{1}$ Hreeshit Kumar and ${ }^{1}$ Sayem Yousuf \\ ${ }^{I}$ Department of Chemical Engineering \\ Bangladesh University of Engineering \& Technology (BUET), Dhaka-1000, Bangladesh \\ ${ }^{2}$ Chief Scientific Officer and Head Radioisotope Production Division (RIPD) \\ Institute of Nuclear Science and Technology, Atomic Energy Research Establishment, Savar, Dhaka,
}

\begin{abstract}
Effect of doping agent on elution profile of Tc-99m generation and labeling of Tc-99m with MDP (Methylene diphosphonate) were carried out and studied. Tc $-99 \mathrm{~m}$ is one of the most talked element of modern radio pharmacy for its multiple application in diagnosis.Tc-99m is produced from Mo-99 through radioactive decay process. In our work two column chromatographic generator were made with Alumina column and loaded with Mo-99 which would be converted into Tc-99m eventually. Elution was taken by passing saline $(1 \mathrm{~mL} 0.9 \% \mathrm{NaCl}$ solution and 1 $\mathrm{mL} 0.9 \% \mathrm{NaCl}$ solution with $0.0045 \% \mathrm{NaNO}_{3}$ as doping agent) each time and the activities of $\mathrm{Tc}-99 \mathrm{~m}$ was measured by a Dose Calibrator. Elutions of Tc-99m were carried out several times and each time activity was measured. It is observed that almost $60-75 \%$ activity can be found in $2^{\text {nd }}$ elution. Studying elution profile it is seen that activity curve reaches at pick in $2^{\text {nd }}$ elution and afterwards gradually slopes down. Each time better activity is achieved by using pure saline. In spite of lower activity, this research resulting highly recommendation of using $\mathrm{NaNO}_{3}$ as a doping agent in $\mathrm{NaCl}$ saline in case of using elution because of its higher purity and RCP value . Tc $99 \mathrm{~m}$ is applied over a biological body as a labeled compound. In this case MDP was used as a labeling compound . With a view of carrying out the RCP value of labeled compound, paper chromatography technique is done with various mobile phases in Whatman No 1 paper. Purity (\%) is ranging from $30-90 \%$ and $\mathrm{NaNO}_{3}$ doped $\mathrm{NaCl}$ radioactive solution shows better purity performance than pure $\mathrm{NaCl}$ solution in every different mobile phase .
\end{abstract}

\section{Introduction}

Technetium- $99 \mathrm{~m}$ is a metastable nuclear isomer of technetium-99, symbolized as ${ }^{99 \mathrm{~m}} \mathrm{Tc}{ }^{[1]}$. The $" \mathrm{~m} "$ indicates that this is a metastable nuclear isomer, i.e., that its half-life of 6 hours is considerably longer (by 14 orders of magnitude, at least) than most nuclear isomers that undergo gamma decay.

Technetium- $99 \mathrm{~m}$ is used as a radioactive tracer that medical equipment can detect in the body. It is well suited to the role because it emits readily detectable $140 \mathrm{keV}$ gamma rays (these are about the same wavelength emitted by conventional X-ray diagnostic equipment), and its half-life for gamma emission is 6.0058 hours (meaning that $93.7 \%$ of it decays to ${ }^{99} \mathrm{Tc}$ in 24 hours). The "short" half-life of the isotope (in terms of human-activity and metabolism) allows for scanning procedures which collect data rapidly, but keep total patient radiation exposure low. Due to its short half-life, technetium-99m for nuclear medicine purposes is usually extracted from technetium-99m generators which contain molybdenum-99 (Mo-99, half-life 2.75 days), which is the usual parent nuclide for this isotope. The majority of Mo-99 produced for Tc-99m medical use comes from fission of HEU (highly enriched uranium) from only five reactors around the world: NRU, Canada; BR2, Belgium; SAFARI-1, South Africa; HFR (Petten), the Netherlands; and the Osiris reactor in Saclay, France. ${ }^{[1][2]}$.In our country Tc-99m is produced from Mo-99 at the laboratory of RIPD division under INST at Savar, Dhaka. Typical quantities of technetium administered for immunoscintigraphy tests, such as SPECT tests, range from 10 to $30 \mathrm{mCi}$ for adults. ${ }^{[3][4]}$ These doses result in radiation exposures to the patient around $10 \mathrm{mSv}$, the equivalent of about 500 chest X-ray exposures. Radiation exposure due to diagnostic treatment involving technetium-99m can be kept low. Because technetium-99m has a short half-life and emits primarily a gamma ray (allowing small amounts to be easily detected), its quick decay into the far-less radioactive technetium-99 results in relatively low total radiation dose to the patient per unit of initial activity after administration, as compared to other radioisotopes. In the form administered in these medical tests (usually pertechnetate), technetium-99m and technetium-99 
are eliminated from the body within a few days. ${ }^{[12]}$ Technetium for nuclear medicine purposes is extracted from technetium-99m generators, because of its short 6-hour half-life. Technetium comes off the generator in the form of the pertechnetate ion, $\mathrm{TcO}_{4}{ }^{-}$.

A ligand is added to form a coordination complex. The oxidation state of $\mathrm{Tc}$ in this compound is +7 . This is not suitable for medical applications. In medical practice, a reducing agent is added to the pertechnetate solution to bring the oxidation state down to +3 or +4 . The ligand is chosen to have an affinity for the specific organ to be targeted. The nuclear medicine technique commonly called the bone scan usually uses Tc-99m taken up by osteoblast cells which build bone. For a bone scan, the patient is injected with a small amount of radioactive material such as $20-30 \mathrm{mCi}$ of technetium-99m-MDP and then scanned with a gamma camera. MDP is a phosphate derivative which can exchange place with bone phosphate in regions of active bone growth, so anchoring the radioisotope to that specific region.

In this study, some vital parameters like elution profile, Mo-99 break through, effect of $\mathrm{NaNO}_{3}$ as doping agent in $\mathrm{NaCl}$ saline, application of kit legand in various mobile phase have been investigated to ensure more efficient practical usage . We studied the effect of doping agent on elution profile of Tc-99m generator and make any recommendation if it is possible to determine the RCP value of labeled compound provided by paper chromatography technique which is done with various mobile phases in Whatman No 1 paper.

\section{Experimental}

\subsection{Preparation of Generator column}

An Aluminium oxide solution of $\mathrm{pH}$ less than 3 is prepared from alumina particle of $100-200$ mesh . Columns were loaded with $\mathrm{Al}_{2} \mathrm{O}_{3}$ solution. After loading, sintered disc, glass wool, rubber stopper were fixed in the column and sealed with $\mathrm{Al}$ cap.

All water from the column was injected out. Needles were settled in the column and glue was attached carefully at the joints to make it completely air resistance .

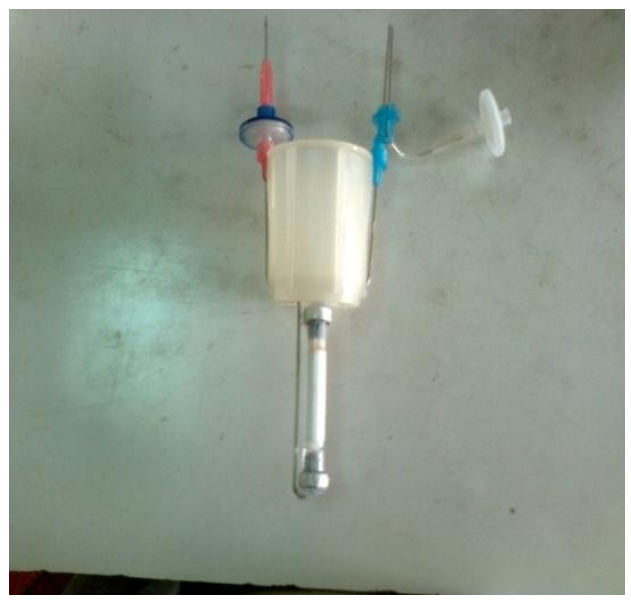

Fig 1 : Tc-99m generator Column fixed with needles

\subsection{Preparation of Physiological saline}

Physiological saline of $0.9 \% \mathrm{NaCl}$ dopping with $\mathrm{NaNO}_{3}(25 \mathrm{mg} / \mathrm{L})$ (Formula: $9 \mathrm{gm} \mathrm{NaCl}+0.045 \mathrm{gm}$ $\mathrm{NaNO}+$ Distilled water 1 litre) and not dopping with $\mathrm{NaNO}_{3}$ (Formula: 9gm NaCl +Distilled water 1 litre) were prepared. Prepared saline was dispensed into vials .

\subsection{Operation of Hot cell}

Mo-99 Transfer and production process were done in the hot cell .

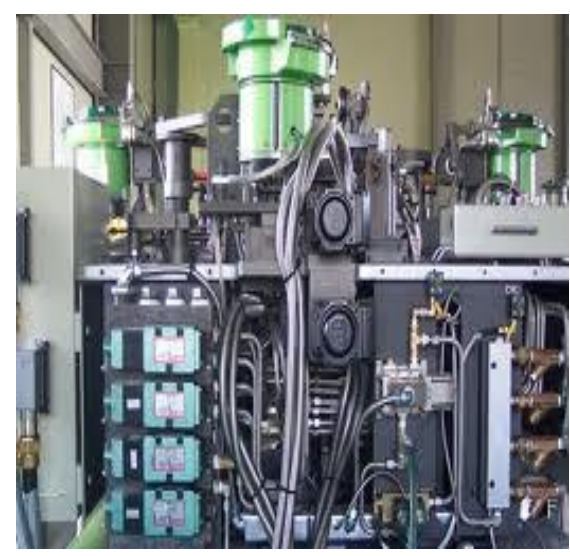

Fig 2 : General view of hot cell 


\subsection{Elution Procedure}

Before of the elution procedure of generator, washing process with saline solution was done to make the Tc-99m level at 0 and to make Mo free product . Because of the defect of alumina column, unabsorbed Mo-99 can co-exist with product Tc-99m which is undesired and known as Mo breakthrough. By washing , unabsorbed Mo-99 was removed away. Elution procedure was started about half an hour after washing.

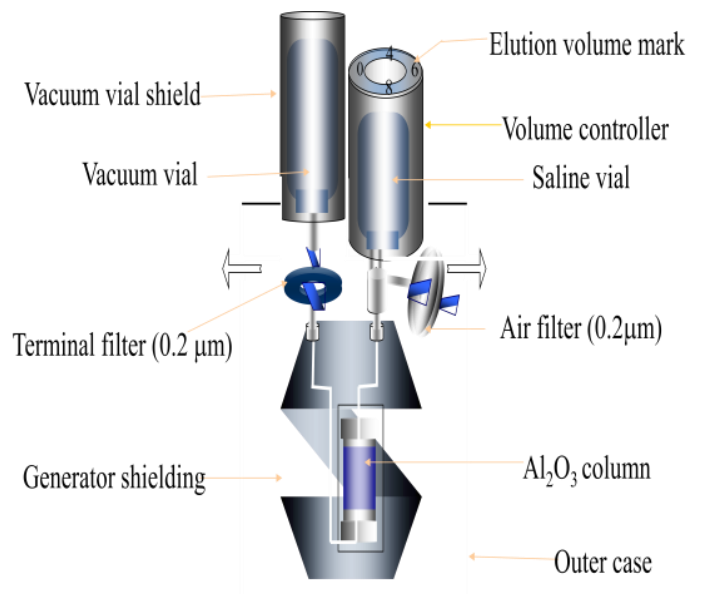

\section{Te.99m Generator System}

Fig 3 : Elution system of Tc $-99 \mathrm{~m}$ generator.

\subsection{Preparation of Labeled compound}

MDP vials from refrigeration stock were taken and adjusted with room temperature. $4 \mathrm{ml}$ solution (3.5 $\mathrm{ml}$ saline+ $0.5 \mathrm{ml}$ solution of TC-99m) was mixed with MDP in a vial.

\subsection{Preparation of Whatman No 1 paper}

Whatman chromatographic paper strip $(10 \mathrm{~cm}$ length, $1 \mathrm{~cm}$ width) was made from whatman paper stock.The paper strips were heated carefully for half an hour. The drawings of droplet point ,indication boundary for top and bottom were drawn over the strip.

\subsection{Soaking process with mobile phase}

All whatman No 1 paper strips were soaked with various mobile phases in different test- tube. After the completion of soaking process, whatman paper strips were taken out from the test-tube and dried carefully.

\subsection{Dropping of Labeled compound}

A very small droplet of labeled compound was dropped over whatman strip at indicated spot. After certain period of time, the diffusion of droplet all over the strip was assured. All the strips were taped with transparent tape .

\subsection{Determination of RCP value}

All taped strips were cut in the middle just dividing them into top and bottom. All top and bottom strips were taken into High Performance Ge (HPGe) detector. RCP values for all strips were measured by HPGe detector.

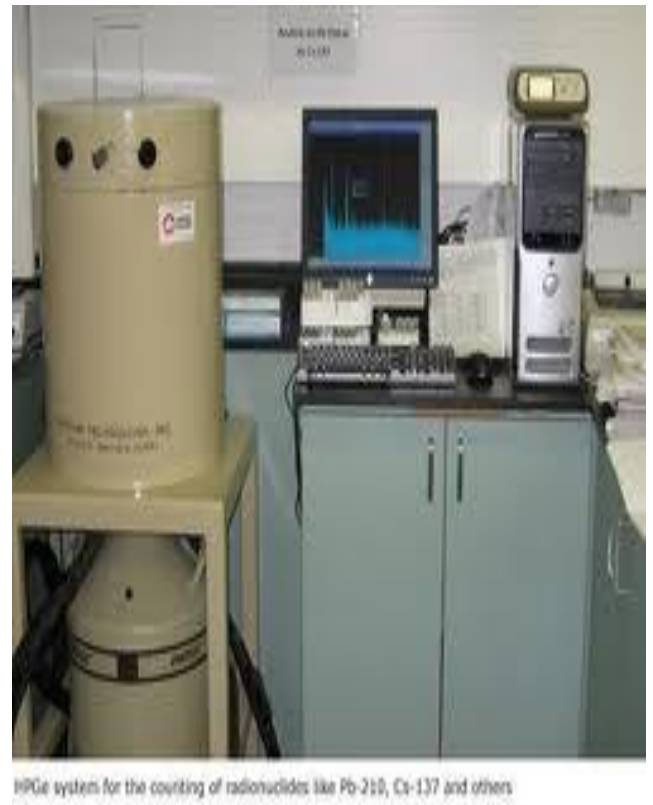

Fig 4 : HPGe Detector 


\section{Results and Discussion}

\section{$\underline{\text { 3.1.Activity Measurement }}$}

Table 1: Measurement of Tc-99m activity by using Nacl saline .

\begin{tabular}{|l|l|l|l|}
\hline $\begin{array}{l}\text { No. of } \\
\text { reading }\end{array}$ & $\begin{array}{l}\text { Volume } \\
\text { of the } \\
\text { eluent } \\
(\mathrm{ml})\end{array}$ & $\begin{array}{l}\text { Activity of } \\
\text { Tc-99m } \\
(\mathrm{m} \mathrm{Ci})\end{array}$ & $\begin{array}{c}\text { \% } \\
\text { Activity } \\
\mathrm{N}_{\mathrm{i}} / \mathrm{N}\end{array}$ \\
\hline 1. & 1 & 7.88 & 0.046 \\
\hline 2. & 2 & 125.3 & 0.74 \\
\hline 3. & 3 & 27.86 & 0.16 \\
\hline 4. & 4 & 4.24 & 0.25 \\
\hline 5. & 5 & 1.49 & 0.009 \\
\hline 6. & 6 & 0.865 & 0.005 \\
\hline 7. & 7 & 0.825 & 0.0048 \\
\hline 8. & 8 & 0.532 & 0.003 \\
\hline & & $\begin{array}{l}\mathrm{N}= \\
168.992\end{array}$ \\
\hline
\end{tabular}

Table 2: Measurement of Tc-99m activity by using $\mathrm{Nacl}+\mathrm{NaNO}_{3}$ saline.

\begin{tabular}{|c|c|c|c|}
\hline $\begin{array}{l}\text { No. of } \\
\text { reading }\end{array}$ & $\begin{array}{l}\text { Volume } \\
\text { of the } \\
\text { eluent } \\
(\mathrm{ml})\end{array}$ & $\begin{array}{l}\text { Activity of } \\
\text { Tc-99m } \\
\text { (m Ci) }\end{array}$ & $\begin{array}{c}(\%) \\
\text { Activity } \\
\mathrm{N}_{\mathrm{i}} / \mathrm{N}\end{array}$ \\
\hline 1. & 1 & 2.63 & 0.0224 \\
\hline 2. & 2 & 78.92 & 0.67 \\
\hline 3. & 3 & 27.27 & 0.23 \\
\hline 4. & 4 & 5.02 & 0.043 \\
\hline 5. & 5 & 1.20 & 0.010 \\
\hline 6. & 6 & 0.639 & 0.0054 \\
\hline 7. & 7 & 0.578 & 0.0049 \\
\hline \multirow[t]{2}{*}{8.} & 8 & 0.702 & 0.0059 \\
\hline & & $\begin{array}{ll}\mathrm{N} & = \\
116.959\end{array}$ & \\
\hline
\end{tabular}

\subsection{Observed data for MDP kit-day 1}

Kit:MDP ,

Stationary phase: Whatman No.1
pH: 6-7

Table 3 :Top and bottom RCP reading for HPGeDetector .

\begin{tabular}{|l|l|l|l|l|}
\hline Batch & $\begin{array}{l}\text { Mobile } \\
\text { phase }\end{array}$ & Sample & Top & Bottom \\
\hline $\begin{array}{l}\mathrm{NaNO}_{3} \\
+\mathrm{NaCl}\end{array}$ & $\mathrm{MEK}$ & 1. & 76 & 15302 \\
\hline & & 2. & 116 & 10266 \\
\hline & $\begin{array}{l}\mathrm{NaNO}_{3}+ \\
\mathrm{NaCl}\end{array}$ & 1. & 8120 & 1105 \\
\cline { 3 - 5 } & & 2. & 8715 & 1058 \\
\hline
\end{tabular}

Purity for sample 1 is $87.52 \%$ and sample 2 is $87.97 \%$

\subsection{Observed data for MDP kit-day 1}

\section{Kit:MDP}

Stationary phase:Whatman No.1

pH: 6-7

Table 4:Top and bottom RCP reading for HPGeDetector

\begin{tabular}{|c|c|c|c|c|}
\hline Batch & $\begin{array}{l}\text { Mobile } \\
\text { phase }\end{array}$ & Sample & Top & Bottom \\
\hline \multirow{4}{*}{$\mathrm{NaCl}$} & \multirow{2}{*}{ MEK } & 1. & 63 & 18640 \\
\hline & & 2. & 48 & 5412 \\
\hline & \multirow[b]{2}{*}{$\begin{array}{l}\mathrm{NaNO}_{3}+ \\
\mathrm{NaCl}\end{array}$} & 1. & 3688 & 821 \\
\hline & & 2. & 6948 & 1317 \\
\hline
\end{tabular}

Purity for sample 1 is $81.43 \%$ and sample 2 is $83.18 \%$ 


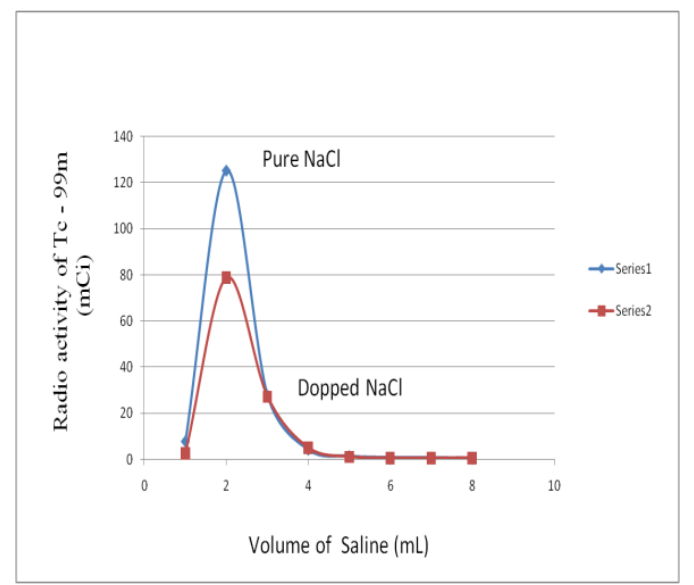

Fig 5: Elution profile comparison of Tc-99m for $\left(\mathrm{NaCl}+\mathrm{NaNO}_{3}\right.$ saline $)$ and pure $\mathrm{NaCl}$ saline .

Elution profile is a graphical output of the Chromatographic column generator which shows how much radioactivity is being carried out of the column by the eluant volume. Elution profile reflects the radioactive concentration which can be obtained from a Tc-99m generator.

In each elution profile the activity amount reaches at highest at $2^{\text {nd }}$ elution not at $1^{\text {st }}$. The fact behind that is the produced $\mathrm{Tc}-99 \mathrm{~m}$ atom sustains a cohesive force between them at column generator. $1^{\text {st }}$ elution of saline is used to break that cohesive force. Then again, at $2^{\text {nd }}$ elution most of the Tc-99m atom is collected. That's why $2^{\text {nd }}$ elution always has highest activity performance.

There can be some impurities which can coexist with the Tc $-99 \mathrm{~m}$ atom at elution solution. Impurities can be identified by RCP values. The more RCP values shows higher purity than less RCP values. The nature of radionuclidic impurities depends mainly on route of production of parent ${ }^{99} \mathrm{Mo}$. Molybdenum-99 itself is a main radionuclidic impurity in ${ }^{99 \mathrm{~m}} \mathrm{Tc}$. The amount of ${ }^{99}$ Mo passes along with the ${ }^{99 \mathrm{~m}} \mathrm{Tc}$ during elution of the chromatographic generator with physiological saline is called ${ }^{99}$ Mo break through.. Break through is one of the most imported quality aspects of the column chromatographic generatoThe others impurity can be mentioned as $\mathrm{TcO}_{4}^{-}$, hydrated Tc etc. The impurities object the diffusion process of Tc $-99 \mathrm{~m}$ at the biological body. For sometimes it can spoil the whole mapping process of radioactivity identification.Adding of doping agent or verifying the eluant solution can make differences of RCP values. Any defects of parent Mo-99 atom and column chromatographic generator are mainly responsible for those impurities.
We can see from the RCP value measurement, $\mathrm{NaCl}$ $+\mathrm{NaNO}_{3}$ saline and pure $\mathrm{NaCl}$ saline with MDP kit day 1 shows purity for sample 1 is $87.52 \%$ and 81.43 $\%$ respectively,for sample 2 it is $87.97 \%$ and 83.18 $\%$ respectively . Again for MDP kit - day $2, \mathrm{NaCl}+$ $\mathrm{NaNO}_{3}$ saline and pure $\mathrm{NaCl}$ saline shows purity for sample 1 is $70.26 \%$ and $31.65 \%$ respectively, for sample 2 it is $80.01 \%$ and $53.91 \%$ respectively . It is also seen that the activity of different elution changes with a regular order. It is quite observant that the highest activity for $\mathrm{NaCl}$ saline is $125.3 \mathrm{mCi}$ and for $\mathrm{Nacl}+\mathrm{NaNO}_{3}$ saline it is $78.92, \mathrm{mCi}$ which is about $74 \%$ and $67 \%$ of total radioactivity respectively that is gained in $2^{\text {nd }}$ elution. After $2^{\text {nd }}$ elution the activity amount starts to fall again. It is strongly recommended to use $\mathrm{NaNO}_{3}$ as a doping agent with $\mathrm{NaCl}$ saline for elution process . As using doping agent better RCP value and purity is gained, though the pure $\mathrm{NaCl}$ shows higher activity .

\section{Conclusion}

By reviewing purity performance values ,It is quite observant that each time better purity performance is achieved by using $\mathrm{NaNO}_{3}$ doped $\mathrm{NaCl}$ solution rather than pure $\mathrm{NaCl}$ solution. This point may suggests the supremacy of $\mathrm{NaNO}_{3}$ doped $\mathrm{NaCl}$ solution over pure Nacl solution in practical use. We hope all obtained values and recommended points will contribute in the production of Tc-99m at Radioisotope Production Division(RIPD), AERE, INST and in their projected future mass production successfully.

\section{References}

1. Bedetti, G.; Pizzi, C.; Gavaruzzi, G.; Lugaresi, F.; Cicognani, A.; Picano, E. (2008). "Suboptimal awareness of radiologic dose among patients undergoing cardiac stress scintigraphy". J Am Coll Radiol 5 (2): 126-31.

2. Joseph F. Smith. "Technetium heart scan".

3. M. Azizul Haque, Radioisotopes generators, Lecture materials for M. Phil in Nuclear Science of BSMMU,Dhaka, 2010.

4. G. SUBRAMANIAN and J. G. Mcafee ,radioisotopes generators in radiopharmacy, by M. Tubis and W. wolf, John wiley . 